\title{
Comercio y contrabando de esmeraldas neogranadinas en Italia meridional: joyería y simbología en la Edad Moderna
}

Trading and Smuggling of Nerw-Granadan Emeralds in Southern Italy: Jewellery and Symbologies in the Modern Age

DOI: https://doi.org/IO.22380/20274688.1947

Recibido: 15 de enero del 2021

FRANCESCO DE NICOLO*

Aprobado: 13 de mayo del 2021

Universidad de Granada, España

denicolo.francesco@yahoo.it

LAURA LILIANA VARGAS**

Becaria Marilynn Thoma Postdoctoral Fellowship

lauralilivm@gmail.com

* Doctorando en Historia del Arte de la Universidad de Granada, España; grado cum laude en Patrimonio Cultural de la Università degli Studi di Bari, Italia; máster cum laude en Historia del Arte de la Università degli Studi di Bari, Italia. Ha colaborado con el Museo Diocesano de Molfetta, con la Pinacoteca Provincial de Bari y con la Superintendencia de Patrimonio Cultural de Bari. Su investigación se dirige hacia el estudio del arte del antiguo reino de Nápoles, así como de la circulación del arte italiano en España y Latinoamérica. En sus ya numerosas publicaciones, ha estudiado el desarrollo de la escultura de madera napolitana desde el siglo XVII hasta el XIX. https://orcid. org/0000-0002-8432-0460

** Becaria Marilynn Thoma Postdoctoral Fellowship; maestra en Artes Plásticas de la Universidad Nacional de Colombia, Bogotá; máster en Instrumentos para la valoración y gestión del patrimonio artístico y doctora en Historia del Arte y Gestión Cultural en el Mundo Hispánico de la Universidad Pablo de Olavide, Sevilla. Miembro del grupo de investigación Estudios Históricos y Artísticos de Bienes Culturales de la Universidad Nacional de Colombia, sede Bogotá. Investigadora del Proyecto Pintura, poder, sociedad y naturaleza en el Quito barroco (Ministerio de Ciencia e Innovación, España, Convocatoria 2020 Proyectos I+D+i, Ref. PID2020-II2852GB-IOO, financiado por MCIN/ AEI/I0.13039/501100011033). http://orcid.org/0000-000I-84II-3085 
Este ensayo se centra en la recepción de esmeraldas neogranadinas en los virreinatos de Sicilia y Nápoles, donde eran talladas para su engaste en obras de joyería y platería como lo demuestran ejemplos emblemáticos, especialmente de índole religioso, conservados en el sur de la península italiana. Alrededor de estas piedras preciosas, generalmente denominadas en Europa "esmeraldas del Perú", se tratarán aspectos relativos a su comercio, contrabando, falsificación y valor simbólico. Por último, se establece una relación entre la custodia de la Compañía de Jesús de Bogotá, conocida como La Lechuga, y un ostensorio napolitano.

Palabras clave: esmeraldas neogranadinas, esmeraldas colombianas, comercio, Italia meridional, joyería, simbología

\section{$\begin{array}{llllllll}A & \mathbf{B} & \mathbf{S} & \mathbf{T} & \mathbf{R} & \mathbf{A} & \mathbf{C} & \mathbf{T}\end{array}$}

This paper focuses on the reception of New Granadan emeralds in the Viceroyalties of Sicily and Naples, where they were carved and set in jewelry and silverware works, as emblematic examples -of mostly religious nature- preserved in southern Italy. This article also examines the trading, smuggling, forgery and the symbolic value of these precious gems, generally called in Europe "Peruvian emeralds". Finally, a relation is established between "La Lechuga" ('The Lettuce'), the custody of the Society of Jesus of Bogota, and a Neapolitan monstrance.

Keywords: New-Granadan emeralds, Colombian emeralds, trade, southern Italy, jewelry, symbology

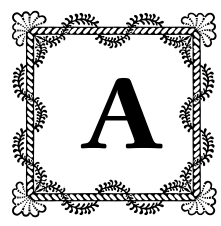

partir del siglo XVI, las minas neogranadinas se convirtieron en las principales proveedoras de esmeraldas en Europa. Este artículo abordará las dinámicas que llevaron a la difusión de estas gemas y su empleo en la joyería de los virreinatos de Nápoles y Sicilia, parte integrante de la monarquía española.

\section{Las esmeraldas neogranadinas}

Con independencia de su lugar de extracción, las esmeraldas hispanoamericanas eran conocidas en Italia y en Europa como esmeraldas de Perú (Haüy 4I). $\mathrm{Su}$ origen era la parte norte del virreinato peruano, correspondiente al Nuevo 
Reino de Granada, donde se hallan las minas de Muzo, Gachalá, Coscuez y Chivor (Colombia) (figura I).

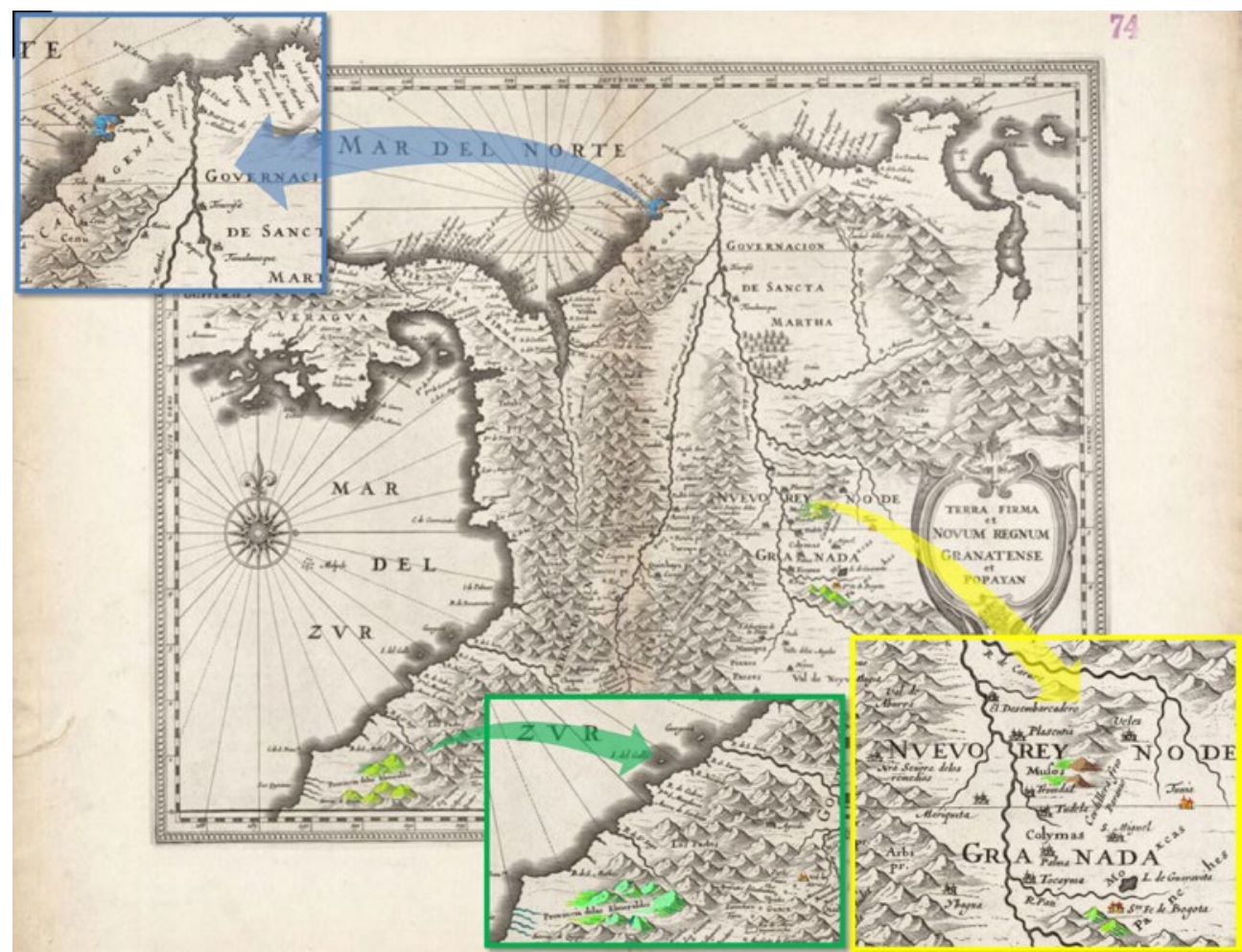

$\rightarrow$ FIGURA I.

Willem Janszoon Blaeu. Terra Firma et Nouum Regnum Granatense et Popayan. I630. $36 \times 47 \mathrm{~cm}$

En este mapa se ubican: la provincia de Los Muzos, el puerto de Cartagena de Indias y la provincia de Las Esmeraldas (iluminación hecha por los autores del artículo)

Fuente: Norman B. Leventhal Map \& Education Center at the Boston Public Library.

En Europa, aún en el siglo Xix, no se tenía claridad sobre la ubicación de las zonas de extracción de esmeraldas, los tratados de mineralogía las localizaban en Manta, en el valle de Tanca [sic] y en Popayán, vetas que ante la imposibilidad de hallarlas se consideraron agotadas (Saggio 3I). Diccionarios de historia natural de amplia circulación continuaban situando esta minería en Manta, añadiendo el Perú, Cartagena y el valle de Tunja como sus lugares de origen (Valmont I62). Y hubo tratados que alabaron su calidad, considerando 
a las gemas "peruanas" verdaderas esmeraldas desde el punto de vista mineralógico (Bossi 18-27).

Es posible que esta confusión se deba a que los joyeros españoles en la segunda mitad del siglo XVI dividían a las esmeraldas en peruanas y en orientales (Lane IOI), y a la confianza dada al inca Garcilaso de La Vega como fuente, quien incluyó a las esmeraldas en Comentarios reales, entre los objetos idolatrados por los indígenas, especialmente en la provincia de Puerto Viejo (De la Vega 36). Como él, otros cronistas referían que era común ver a los indios de Manta y Esmeraldas (actual Ecuador) con cantidades de estas piedras, por lo que pensaron debía existir una mina próxima a estos lugares (Lane 24-25). Lucas Fernández de Piedrahita, en la segunda mitad del xviI, contradice al inca, identificando a las minas de Muzo y de Somondoco como las productoras de esmeraldas que "exceden a las del Oriente con muchas ventajas", y afirma que muchas de estas gemas, que se las había visto a los comerciantes portugueses, no eran del Oriente, específicamente del Reino de Narsinga, como afirmaban, sino que provenían de Muzo (Fernández 7, 156, 157). Narraciones relacionadas con el descubrimiento de ambas minas pueden encontrarse en la Recopilación historial de fray Pedro de Aguado (I43-I48, 285). La comprobación mediante observaciones de expertos gemólogos y de pruebas de laboratorio de que las esmeraldas que circulaban desde épocas prehispánicas por América tenían origen en la zona boyacense y cundinamarquesa ayuda a desmentir la creencia en la existencia de minas perdidas o agotadas en Ecuador y en Perú (Lane 38).

Numerosos cronistas destacaron la riqueza esmeraldífera neogranadina, cuyo descubrimiento se ha datado hacia I5I4, cuando los conquistadores en Santa Marta notaron que los indígenas poseían numerosas piedras, y a partir de ese momento fueron llevadas en cantidades a Europa, a tal punto que Gonzalo Fernández de Oviedo, en I535, afirmó que se habían llevado tantas que sus precios cayeron en el mercado europeo; el primer cargamento de estas gemas a España se les atribuye a Quesada, Belalcázar y Federman. También el misionero José de Acosta (I539-I600) testimonia que en el año 1587 la nave en la que estaba embarcado para volver a Espańa transportaba "dos cajones de esmeraldas, que tenía cada uno dellos por lo menos cuatro arrobas, por donde se puede ver la abundancia que hay" (Acosta ir6).

El hallazgo por parte de Pedro Hernández de Valenzuela y Antonio Díaz de Quesada de las minas de Chivor se fecha en 1537, pero su explotación no fue constante durante el periodo virreinal, su beneficio se concentró entre 1592 y I672, fecha de su cierre. En cuanto a las minas de Muzo, en I55I se comunicó a 
la Corona la apertura de estas en medio de constantes luchas por el territorio contra los indios muzos. Otro de los grandes yacimientos fue el de Itoco, que inició su explotación en 1567.

Los cinturones esmeraldíferos colombianos localizados en los actuales departamentos de Boyacá, Cundinamarca y Santander, según el modelo más aceptado por Ingeominas (actualmente Servicio Geológico Colombiano), se formaron por:

[...] infiltraciones de fluidos hidrotermales en zonas de fractura, que conforman sistemas de venas que desarrollan un intenso halo producido por metasomatismo sódico y carbonatado dentro de las lutitas negras cretácicas encajantes. La lixiviación de casi todos los elementos mayores, elementos trazas y las tierras raras es acompañada por su redistribución parcial dentro del relleno mineral de las venas [...] (Giuliani et al., "Geoquímica" 7)

Además de Colombia, se han hallado minas en Pakistán, Afganistán, Rusia y Austria, y recientemente en Madagascar, África Central y del Sur, Brasil y Estados Unidos (Lane 26-27); también se han detectado existencias menores en Egipto, India y Kazajstán, entre otros (Gavrilenko I9). La identificación del origen geográfico de las esmeraldas es posible gracias al estudio de tres parámetros: el doblete de Fermi en espectrometría Raman, rayos X de tipo dispersivo y señales de agua deuterada en espectrometría infrarroja (CDTEC). Este tipo de estudios ha permitido comprobar el origen colombiano de esmeraldas engastadas en orfebrería americana, europea y asiática. En el año 2000, Gaston Giuliani y otros investigadores determinaron el origen de varias esmeraldas usando isótopos de oxígeno I8, entre ellas gemas que se conservaban en la India, provenientes de las minas de Peñas Blancas, Coscuez, Muzo (estas tres en Colombia) y Afganistán, mientras que el análisis de una de estas piedras preciosas rescatadas de la embarcación naufragada en I622, Nuestra Señora de Atocha, arrojó como resultado que fue extraída de la mina Tequendama de Muzo (Lane 124; Giuliani et al., "Oxygen" 63I-633) 


\section{La circulación de las esmeraldas}

\section{Comercio y contrabando}

Las esmeraldas eran un bien atractivo para el comercio y por ende para el contrabando, la Corona desde muy temprano intentó proteger las explotaciones de Muzo del comercio ilegal, el cual causaba detrimento en sus quintos. En I566 se expidió una real cédula para "que ningún [h]ombre extranjero ni platero ni lapidario entre en la dicha provincia y que si alguno entrare sea preso" (AGN, $M B$, sC. 38, 3, D. IO, f. I84 r.), lo que indica que la adquisición de estas gemas - para ser talladas en Venecia o Nápoles - se lograría por medio de la compra legal en la península española o por el contrabando, pero no por beneficio o compra directa en la zona de extracción.

Dentro de las observaciones del lapidario italiano Pedro Puch, en un informe de 1767 sobre las perlas y las esmeraldas del Nuevo Reino de Granada, se destacaba que las esmeraldas enviadas a España desde Cartagena de Indias eran de menor calidad que las que se podían encontrar en Holanda e Inglaterra, también de origen neogranadino, lo cual era un indicio de su contrabando, y se extrañaba del poco control que se hacía de la explotación y comercio de estas. En este escrito, dirigido a José de Gálvez, presidente del Consejo de Indias, Puch elogió la calidad de las esmeraldas neogranadinas, subrayando que esta opinión se sustentaba en 42 años de experiencia en el labrado y la tasación de piedras en Londres, La Haya y otras ciudades europeas, así como en su estadía en el Nuevo Reino durante siete meses en 1766 (Paniagua 176). En 1782, Puch analizó que los cortes de unas morrallas arribadas a la península española eran indicio del engaño hecho a los directores de las minas ya que suponía que antes de entregar las esmeraldas, los lapidarios se apropiaban de "lo más purificado", dejando lo más ordinario y de peor color, y según sus averiguaciones las mejores piedras eran vendidas por comerciantes holandeses en Curaçao (Domínguez 45-46).

Es posible que el contrabando de esmeraldas se viera favorecido por la dificultad de valorar su calidad, pues a diferencia del oro y la plata, el peso no se podía usar como factor de cálculo para registrarlas en los puertos ${ }^{\mathrm{I}}$. Ejemplo de ello es un caso de 1537, en el cual el tesorero y el contador de la Casa de Contratación informaban al rey sobre unas esmeraldas que se le hallaron en

I A pesar de usarse el quilate como unidad de peso de las piedras preciosas, son otras las características que dan valor a una esmeralda. 
Lisboa a un individuo "florentino o genovés", sobre las cuales no había pagado derechos por no ser oro ni plata; la Casa consideraba que debía pagar dos mil o tres mil ducados (AGI, $I$, IO92, n. ${ }^{\circ} 223$ ).

El "descamino", como se llamaba a este fraude, fue una preocupación constante para la Corona, por lo que en I6I4 Juan Villabona, por medio de unas ordenanzas, estableció que las esmeraldas debían ser registradas en un libro en la misma mina para ser quintadas y depositadas en la Caja Real, por lo que para que pudieran ser vendidas y talladas por lapidarios debían tener certificados de los oficiales reales, en los que se apuntaba el peso de las gemas y la constancia de pago del quinto, además del aporte de fianzas para evitar fugas (Puche IO3).

La comparación de la cantidad de esmeraldas recuperadas del galeón naufragado Nuestra Señora de Atocha con el registro de la carga indica que alrededor de 6000 gemas fueron embarcadas de contrabando; uno de los sobrevivientes declaró haberle ayudado al capitán a introducir 30 kilos de piedras de Muzo de manera ilegal (De Narváez). De estas esmeraldas, muy pocas estaban facetadas (Lane 9I), lo que muestra que iban a ser vendidas a lapidarios europeos o asiáticos para ser engastadas.

Había cuatro categorías de esmeraldas: las de más alta calidad eran las gota de aceite, ta mbién llamadas piedras de cuenta o de primera suerte; las esmeraldas de segunda suerte eran muy buenas y presentaban pocos jardines; las de calidad media y más comunes eran las de tercera suerte; las peores eran las plasma, hoy conocidas como morrallas (De Narváez). Pese a que los análisis científicos han comprobado que las esmeraldas de mejor calidad halladas en obras de orfebrería europea y asiática eran neogranadinas, en Europa se pensaba que las gemas de primera y segunda suerte eran orientales (Lane IOI).

\section{Rutas}

En Il nuovo lume delle gioie, publicado en I682, el joyero de Mantua, Pietro Caliari, señala como principal región de procedencia de las esmeraldas que se encontraban en Italia las "Indie nove onde li Spagnoli che ne sono patroni ne portano quantità" (35). En cambio, en otro libro fechado en I820 se constata que en aquella época muchos revendedores creían que las esmeraldas, sobre todo las de color más vivo, eran de origen asiático y por eso las llamaban orientales. El anónimo autor observa que los muchos naturalistas y exploradores, y en particular Jean-Baptiste Tavernier (I605-I689) que había viajado por toda Asia, 
aseguraban que ni en el continente ni en las islas había sido posible encontrar alguna mina que produjera esmeraldas, añadiendo que las que estaban presentes en Asia "furono portati dopo la scoperta dell'America, dal mare del Sud, dal Perù, o dalle Isole Filippine", y luego, en un segundo momento, desde los mercados asiáticos habían pasado a Europa (Saggio 32).

Lane ha demostrado que las esmeraldas colombianas, a partir del siglo XVII, llegaban en cantidad al emporio portugués de Goa, para satisfacer las exigencias de la dinastía Mughal y del Imperio safávida y, desde el siglo xvinI, la del Imperio otomano. El paso de las esmeraldas a través del océano Atlántico y el Índico, o por vía terrestre, en gran parte se hacía gracias a redes de familias sefardíes ubicadas principalmente en Lisboa, Sevilla y Amberes, llegando a ser Ámsterdam el principal centro de comercio de gemas hacia I600 y Londres alrededor de I655. A mediados del siglo XVII, las familias askenazíes de Hamburgo tuvieron un papel principal en las ventas de piedras preciosas por sus enlaces con Cartagena de Indias, Luanda y Goa, y específicamente en la península italiana con Venecia y Livorno. En el siglo XviII, los mercaderes de joyas genoveses y venecianos tuvieron una relevante participación en Goa (Lane 94-96, I43-160). A través de las caravanas, las esmeraldas junto con perlas, rubíes y otras piedras llegaban a Aleppo y a Venecia, ciudad donde estaba consolidada la tradición del tallado de las piedras entre las familias judías (Trivellato 236). Precisamente la Serenísima, a principios del siglo xviI, tenía el predominio sobre los puertos indios y árabes para la compra de piedras en bruto que luego eran talladas por los maestros venecianos o enviadas para el tallado a Florencia o a Nápoles (Paolillo I60).

Las esmeraldas del Perú se embarcaban también por vía legal desde Cartagena de Indias y llegaban a Europa llevadas por barcos españoles (Valmont I6I). Desde la península ibérica las gemas llegaban a Italia por medio de los mercaderes genoveses ${ }^{2}$ o por contrabando. Era usual que los marineros españoles ocultaran parte del cargamento de los galeones, con el propósito de vender en secreto las esmeraldas en puertos del Mediterráneo como Génova, Nápoles o Palermo (Paolillo I6I). Se conoce el encargo al joyero napolitano Matteo Treglia, por parte de la Diputación del Tesoro de San Genaro en 1712, a fin de realizar una nueva mitra destinada al busto relicario del patrón de Nápoles y del Virreinato.

2 Como ilustra Salvemini, los genoveses procedentes de los puertos ligures de Laigueglia, Diano, Cervo y Porto Maurizio usaban pequeñas embarcaciones para atracar en aldeas costeras o puertos de campo eludiendo los controles y los impuestos de aduana de los puertos mayores (Salvemini 7-5I). 
Para la compra de las gemas necesarias para embellecer el tocado episcopal, Treglia se dirigió a los grandes comerciantes de piedras, quienes a su vez eran abastecidos por los comerciantes genoveses que con su flota importaban de los puertos españoles las mercancías procedente del Nuevo Mundo (Paolillo i6I).

\section{Cortes y falsificaciones}

Los artesanos de Venecia eran hábiles en el trabajo de las piedras duras porque conocían los principios de refracción de los cristales de Euclides y Pitágoras (Paolillo I60). Los lapidarios venecianos, sobre todo pertenecientes a familias judías, eran capaces de dar a las esmeraldas un alto grado de limpieza, hasta el punto de hacerlas lucir brillantes como diamantes, por lo que fueron conocidas como "diamanti di Venezia" (Caliari 36). Los cortes más utilizados fueron los de forma cuadrangular (cuadrada o rectangular) u octogonal (cuadrados o rectángulos con esquinas troncas) ${ }^{3}$. Este último fue el corte más común y tomó el nombre de "corte esmeralda" porque era el que más potenciaba las propiedades ópticas de la piedra (Caliari 37; Scandale II2-II4). Una pied ra bien tallada debe tener las facetas de la culata en los ángulos precisos para devolver toda la luz que entra por la tabla, sin embargo, no es raro encontrar esmeraldas talladas en cabujón, es decir, con la superficie curva (IGE).

En Italia fue rara la aplicación del arte glíptico sobre las esmeraldas, como en el caso de una gema americana incrustada en el collar de san Bruno perteneciente al busto de plata que se venera en Serra San Bruno en Calabria (figura 2), donde la piedra lleva el perfil, más bien caricaturesco, de un prelado que, a falta de documentos, no sabemos si identificar con el desconocido comitente del collar o con otro individuo (Pisani 262).

El uso de una amplia variedad de técnicas, capaces de producir diversos lenguajes estéticos y estilísticos, era la preocupación constante de los maestros orfebres y de los lapidarios que mediante las gemas y sus propiedades ópticas deseaban superar los límites de la monocromaticidad del oro y de la plata en los que estaban engastadas (Franchi, "L'estetica" IO2).

3 Sobre el proceso de talla cuadrada de una esmeralda véase Rojas (20-29). Para conocer las proporciones ideales de las facetas y la geometría del corte de una esmeralda, véase Martín (220-22I). 


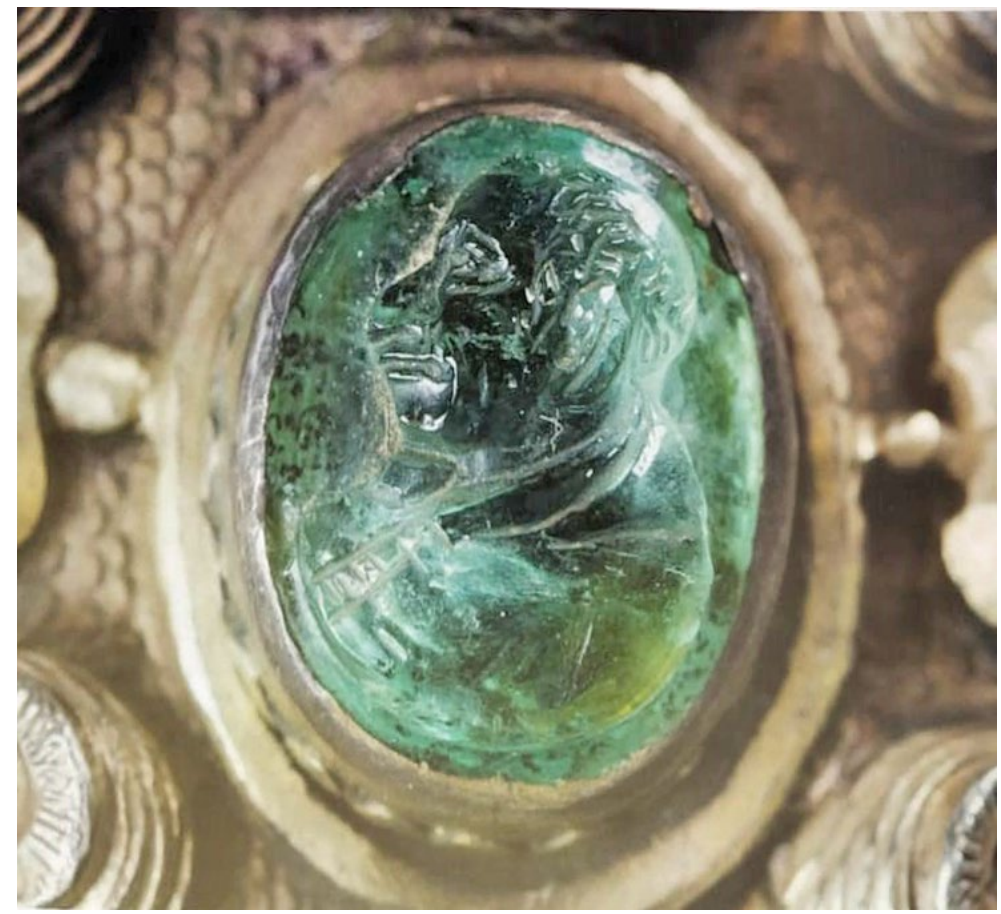

\section{$\rightarrow$ FIGURA 2.}

Manufactura de Italia meridional. Esmeralda del collar de san Bruno. Cartuja, Serra San Bruno. Certosini a Serra San Bruno: il patrimonio storico e artistico

Fuente: fotografía de Domenico Pisani.

Además de Venecia, las esmeraldas se cortaban en Florencia y Nápoles, ciudades en las que operaban centros especializados en las labores de las piedras duras. El Real Laboratorio de Piedras Duras de Nápoles fue fundado en 1737 por Carlos III de Borbón sobre el modelo del Opificio mediceo, del cual procedían los primeros maestros (Ruotolo, "Manifatture reali" 4I). Sin embargo, en la ciudad del Vesubio los lapicidas florentinos, así como los romanos, ya están documentados desde el siglo xviı para la realización de embutidos marmóreos y decoración en equipos con fundidores, orfebres y joyeros de los ciborios de algunas iglesias teatinas (Ruotolo, "Alle origini" I05-II3). La disponibilidad de las esmeraldas implicó una especialización de los artesanos napolitanos: solo los orfebres inscritos en el gremio fueron autorizados a montar las piedras preciosas (Mavelli, "Sacri splendori" 306).

Un fenómeno para tener en cuenta es el de la realización y el tallado de piedras falsas vendidas como esmeraldas a los inadvertidos compradores, hecho denunciado por Giovanni Robbio, quien advertía que "se ne fanno de' falsi, che 
sembrano buoni" hechos "di vetro, di pasta, e delle doppie di cristallo" (554). Vincenzo Pini afirmaba que "lo smeraldo è una pietra, che si contrafà agevolmente col vetro di piombo" y explicaba al detalle el procedimiento por el que "si lavorerà il vetro e se ne faranno lavori di una bellezza non inferiore a quella degli smeraldi orientali. Sostituendo alle scaglie di rame la medesima qualità del capo morto del vitriolo di venere preparato, si ottiene un vetro di smeraldo ancora più bello" (280).

El procedimiento de doblete consistía en pegar láminas de piedras duras sobre pastas vítreas. Para la imitación de las esmeraldas se usaban generalmente dos partes de cuarzo o de berilo natural incoloro, cementadas por una masilla verde, o dos partes de espinela sintética incolora cementadas por una masilla verde (Scandale IIo).

Tanto Pietro Caliari (37-38) como Robbio afirmaban que el nivel de falsificación había llegado a tal punto que se imitaban las imperfecciones presentes en las esmeraldas (el "jardín”), así que "il compratore ingannato dai difetti, gli crede fini, ma al peso, e alla pruova, si trovano falsi” (Robbio 554). Una forma simple de distinguir las esmeraldas falsas era el pesaje, ya que el vidrio es más ligero, mientras que la esmeralda del Perú posee un peso específico de $2732 \mathrm{~g} / \mathrm{cm}^{3}$ (Caliari 38; Pompa 979; Robbio 554). Aparte del fraude, los dobletes y los vidrios de colores fueron hechos para adornar, lícitamente, joyas destinadas a grupos sociales menos ricos, aunque deseosos de exhibir artefactos con materiales de valor más bajo, pero agradables y llamativos como las joyas de la aristocracia (Mavelli, "Le oreficerie" 34).

En España, era Pedro Puch quien en 1788 intentaba hacer "strass", imitaciones de piedras preciosas con la fórmula de vidrio y plomo de Frédéric Strass (Paniagua 184). En la actualidad se obtienen esmeraldas sintéticas por medio del método de flujo y del hidrotermal.

4 Gavrilenko determinó que las inclusiones de las esmeraldas de Muzo y Chivor presentan calcita, dolomita, albita, cuarzo, pirita, barita y berilo (290) y que bajo observación en el microscopio óptico, en las esmeraldas colombianas se detectan inclusiones trifásicas. Las gemas nigerianas pueden presentar jardines semejantes, por lo que su diferenciación requeriría algún método adicional (294). 


\section{Obras}

En Europa, las investigaciones sobre obras de orfebrería y platería ornamentadas con esmeraldas se han realizado principalmente en España; aún no se conoce el verdadero impacto que tuvieron estas gemas neogranadinas en la joyería de otras regiones del continente. Aproximarse al estudio de la difusión de las esmeraldas del Perú en la Italia meridional significa acercarse a las artes de la platería y de la joyería que más requerían su empleo. Se debe recordar que lo que existe actualmente es solo una pequeña parte de un patrimonio que en la Edad Moderna debía ser considerable. En efecto, en el Reino de Nápoles, para hacer frente a los daños del terremoto de 1783 , como también para financiar la guerra contra Francia, el rey Fernando IV dispuso la confiscación de todo el metal que se podía monetizar (1798). A esta "gran fusión" siguieron, en I799, los saqueos realizados por las tropas invasoras francesas y, durante el decenio napoleónico, las requisiciones de los tesoros conservados en los monasterios y conventos suprimidos (Catello, "Il primato" 69; Mavelli, "Oreficeria" 238). Las joyas a lo largo de los siglos han sido objeto de dispersiones, desmontajes, fusiones y cambios que han alterado su aspecto como portador de las modas y del gusto de la época. A pesar de las requisiciones, los ajuares eclesiásticos siguen siendo lugares privilegiados para la conservación de la platería y de la joyería, por lo tanto, obligatorios para el estudio de la circulación de las esmeraldas en Italia.

Normalmente, las esmeraldas están presentes en estos tesoros en forma de piedra tallada, sin embargo, se tiene noticia de una veta de esmeraldas donada al santuario de la Santa Casa de Loreto. La donación es recordada por Caliari quien testifica que el donante, Pedro Antonio de Aragón (I6II-I690), virrey de Nápoles y embajador del rey de España en la Santa Sede, le había mostrado "un sasso che li volse quattro persone à portarlo per farmelo vedere è questo era in forma di un monte, è quello era un pezzo di Rocha di Smeraldo dove si vedeva dentro tochi di Smeraldi di bella grosseza" (Caliari 35-36). El obsequio está confirmado por las fuentes teatinas, las cuales certifican que

a dì I8. di Febbraio 167I. in Loreto [...] habbiam ricevuto [...] un globo di pietra d'altezza circa due palmi, e larghezza d'un palmo e mezzo, restringendosi a piramide, colla prospettiva granita o tempestata naturalmente tutta di smeraldi grossi e piccoli, al numero di cento venti otto: il qual regalo s'è offerto alla santissima Vergine, e riposto nel tesoro. (Maggio IO5) 
Ignoramos cuáles fueron las vicisitudes del mineral que quizás fue robado por las tropas francesas de ocupación que en 1797 saquearon Loreto y su santuario, o fue tomado por los mismos rectores para hacer frente a los problemas económicoss.

A otro virrey de Nápoles, Francisco Ruiz de Castro (I579-I637), se debe la donación de las esmeraldas que adornan el anillo, el collar y la cruz pectoral en oro (figura 3) del simulacro de plata de san Cataldo, patrón de la ciudad de Taranto. El conjunto fue realizado como signo de devoción al santo durante el episcopado de Juan de Castro, hermano del virrey, arzobispo desde I6oo hasta su muerte sobrevenida el año siguiente. La obra, probablemente trabajo de un orfebre meridional, presenta una cruz pectoral adornada con doce esmeraldas y un collar con noventa esmeraldas (Museo Diocesano 85), anticipando varias décadas las soluciones estéticas del collar de San Genaro, del que se hablará más adelante.

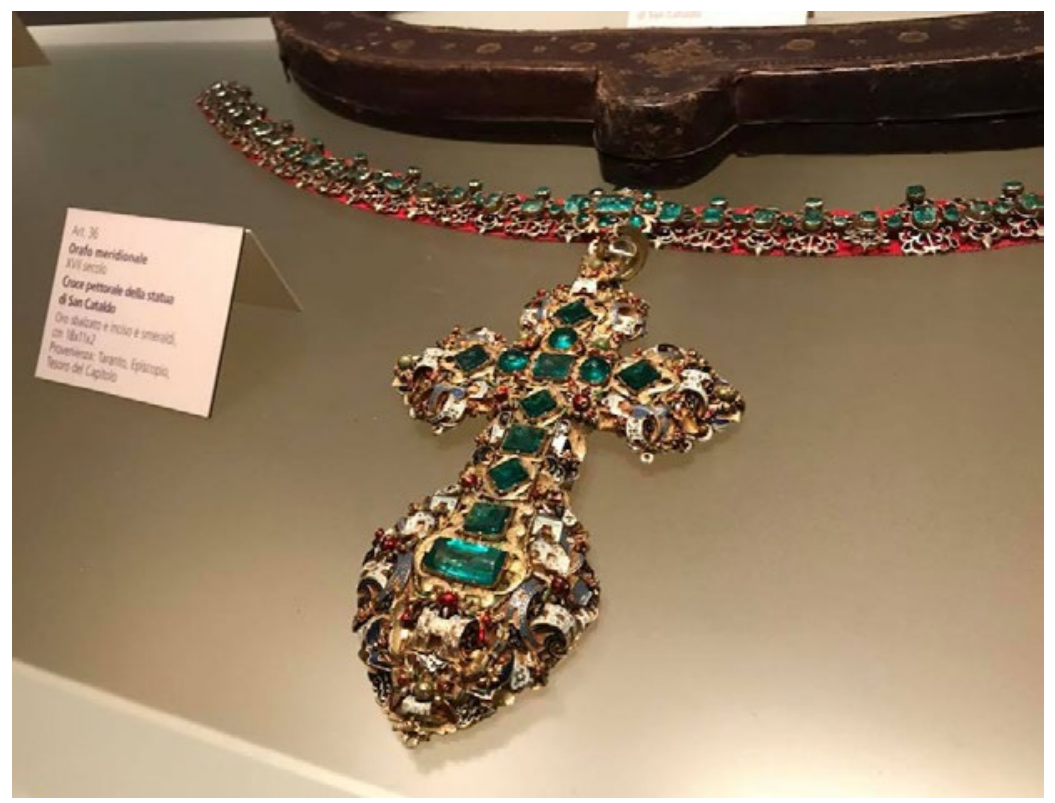

$\bullet$ FIGURA 3 .

Orfebre de Italia meridional. Collar y cruz pectoral de San Cataldo. ca. I6oo. Oro grabado y calado, esmeraldas. Museo Diocesano, Taranto Fuente: fotografía de Francesco De Nicolo.

5 Según antiguos inventarios, el tesoro lauretano guardaba otras joyas adornadas con esmeraldas (Murri 159-207). Al menos hasta 1791, el masso minerale donado por el virrey estaba dentro del armario número XXXII (Murri 197). 
Con referencia a otros encargos costeados por virreyes, se encuentra el de Francisco Benavides y Dávila, conde de Santisteban y virrey de Nápoles (I687I696), quien en 1695 contrató al napolitano Lorenzo Vaccaro (1655-1706) para la realización de cuatro figuras alegóricas de las partes del mundo, que tuvo como destinataria a la reina Mariana de Neoburgo, esposa de Carlos II, y que hoy hacen parte de la colección de la Catedral Primada de Toledo (Martínez 367). La imagen de América (figuras 4, 5 y 6), además de los atributos que Cesare Ripa confiere a este continente, destaca por la cantidad de esmeraldas que porta esta escultura de plata, repartidas en el tocado, el collar, la cinta que cae sobre el pecho, los brazaletes, las pulseras, los lazos y los adornos del calzado. Los cuatro continentes tienen en común la ornamentación con diamantes, pero a cada uno se le asignó una piedra predominante como elemento representativo, así, Europa lleva rubíes, Asia tiene zafiros, África luce topacios y América ostenta esmeraldas (Martínez 373). El testamento de la reina, quien murió en I740, contenía entre sus voluntades que este conjunto fuera legado a Nuestra Señora del Sagrario de Toledo (Martínez 372), por lo cual, al entregarlo en i74I se levantó un inventario en el que se describe la alegoría como una representación de América, sentada en un globo apoyado sobre tres caimanes, con ornamentos que llevan dieciocho diamantes y 618 esmeraldas, además de piezas sueltas con 288 esmeraldas y 188 diamantes (Martínez 374).

En 1790 , el cardenal Lorenzana inventaría las obras de la catedral, dejando testimonio de la existencia de 206 diamantes y 893 esmeraldas (García e Illescas II, I5).

Una curiosa historia en torno a una obra de platería, supuestamente italiana, que ostentaba esmeraldas, es la que se relata en Anserma, Caldas. La tradición narra que Santa Ana de los Caballeros, como se llamaba esta población, recibió como obsequio por parte de Carlos II, en I666, una custodia que habría sido realizada por Benvenuto Cellini, la cual este orfebre le habría regalado al emperador Carlos V (Tafur 406-407). No hay pruebas que corroboren la autoría de Cellini y no se conocen dibujos de la obra, que fue robada en I859. De esta queda la descripción que se publicó en un edicto publicado en la Gaceta del Cauca con motivo del hurto en la iglesia, según la cual era de plata sobredorada, pesaba catorce libras, tenía seis caras en la parte superior y sobre estas una media esfera cóncava con los cuatro evangelistas y un crucifijo, y en el interior colgaban campanillas, la hostia se exponía en una media luna de oro con trece esmeraldas engastadas y perlas, y en el pie redondo estaban los doce apóstoles de medio relieve (Tafur 408). 

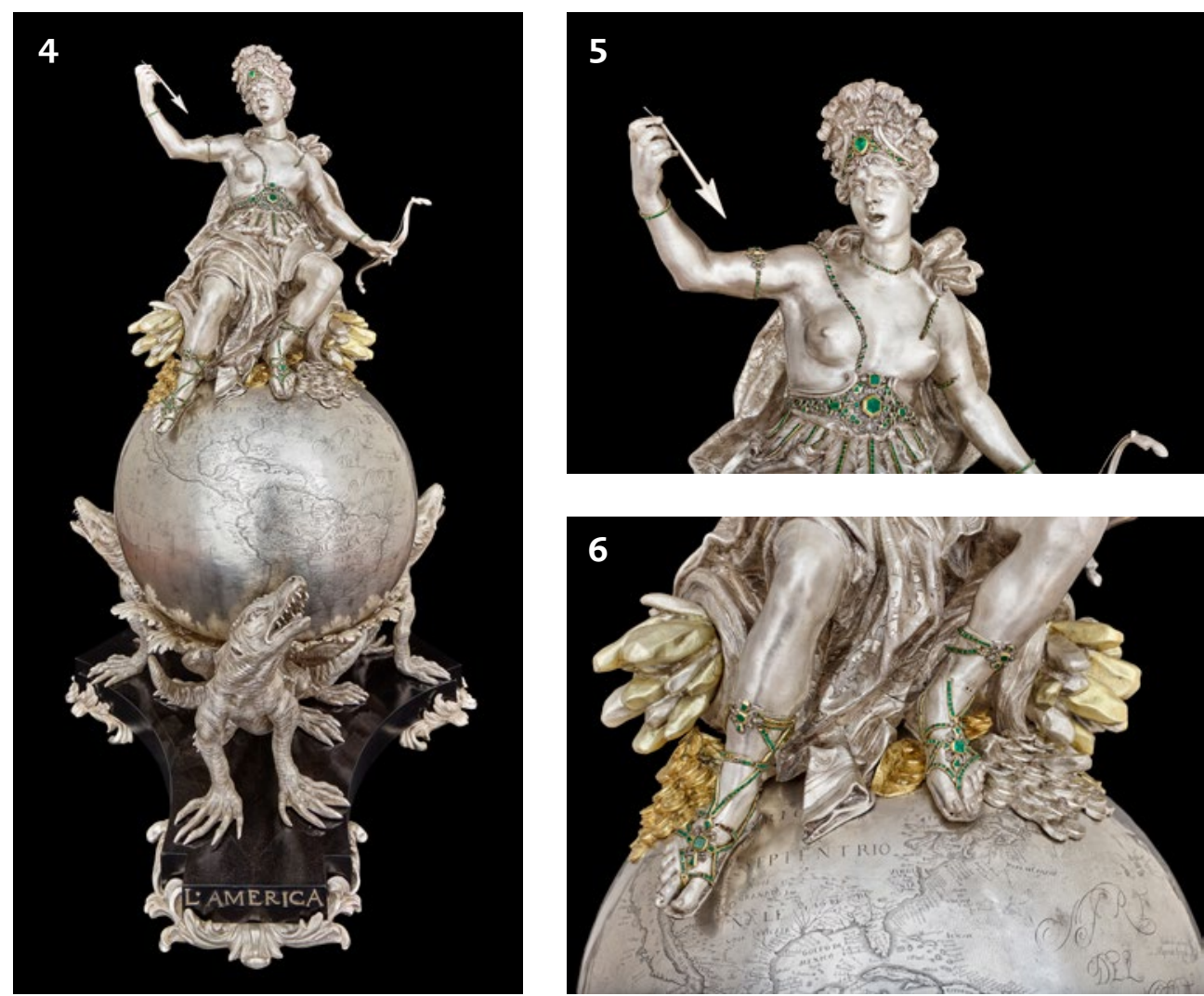

$\rightarrow$ FIGURA 4 .

Lorenzo Vaccaro. América. I695. Plata, esmeraldas, diamantes.

I36 x 70 x $80 \mathrm{~cm}, 45 \mathrm{~kg}$. aprox. (c) Cabildo Catedral Primada, Toledo

Fuente: fotografía de David Blázquez.

$\rightarrow$ FIGURA 5 .

Lorenzo Vaccaro. Detalle con esmeraldas. América. I695. @ Cabildo

Catedral Primada, Toledo

Fuente: fotografía de David Blázquez.

$\rightarrow$ FIGURA 6.

Lorenzo Vaccaro. Detalle con esmeraldas. América. I695. (c Cabildo Catedral Primada, Toledo

Fuente: fotografía de David Blázquez. 
Una parte de las esmeraldas conservada en los tesoros eclesiásticos está ligada a la dádiva, categoría dentro de las oraciones materializadas, expresión de una sociedad aún lejana de conceder privilegio absoluto a la oración (Gri 75). La tradición de obsequiar joyas a un santo encuentra en la Virgen de Trapani un caso llamativo, al haber recogido ex votos de los personajes ilustres de la aristocracia y del clero un flujo de donaciones del siglo xvi en adelante que brinda una aportación para el estudio de la joyería siciliana. Entre las obras se encuentra una cruz pectoral de oro embellecida con doce esmeraldas y con diamantes, la cual cuenta con cabezales de cruz azulados a la manera de las cruces españolas. Esta cruz fue donada por monseñor Giovanni Roano, arzobispo de Monreale entre I673 y 1703 y obispo de Cefalù. Su predilección por las gemas verdes se confirma en sus paramentos litúrgicos conservados en el tesoro de la catedral de Monreale, que están decorados con estas piedras (Di Natale, "Il canónico" I40; Di Natale, Gioielli I64-I65). También del tesoro trapanese proviene la cruz pectoral adornada con esmeraldas y esmaltada en la parte posterior que se abre para asumir la función de relicario, realizada por un orfebre siciliano de la segunda mitad del siglo xviı y donada por D. Antonio Tipa (Di Natale, Gioielli I63-I64). Entre las joyas que adornaban el simulacro de mármol tallado por Nino Pisano alrededor de 1360 , varias fueron donadas por nobles damas, como, por ejemplo, la virreina duquesa de Uzeda Isabel María de Sandoval y Girón, consorte del virrey de Sicilia Juan Francisco Pacheco (I649-I7I8), quien en 1696 donó a la Virgen de Trapani "una gioia grande fatta a fiore con trecentotrentaquattro diamanti e ottanta smeraldi grossi" (figura 7), muy similar a la "gioia di smeraldi" que la misma virreina había obsequiado a la Virgen de la Lettera de Mesina el año anterior (Di Natale, "I doni" 262). Tales donaciones no se deben leer simplemente desde la óptica do ut des, sino bajo la de un verdadero pacto de alianza y fidelidad eterna entre el donante y la divinidad (Tripputi 99).

De gran similitud a las joyas donadas por la duquesa de Uzeda es la fíbula de la capa pluvial del tesoro de la catedral de Palermo, formada por una cinta que encierra tallos de tulipanes decorados con esmeraldas, quizás ejecutada por voluntad del arzobispo de Palermo Ferdinando Bazan y Manríquez (Di Natale, Gioielli 196; Di Natale, "Ori" 82).

Los tesoros sicilianos han sido estudiados a fondo por María Concetta Di Natale, autora de una importante monografía sobre la joya siciliana, en la cual se publican numerosas joyas decoradas con esmeraldas. Ante la imposibilidad de levantar una lista completa de todos las joyas con esmeraldas halladas en 


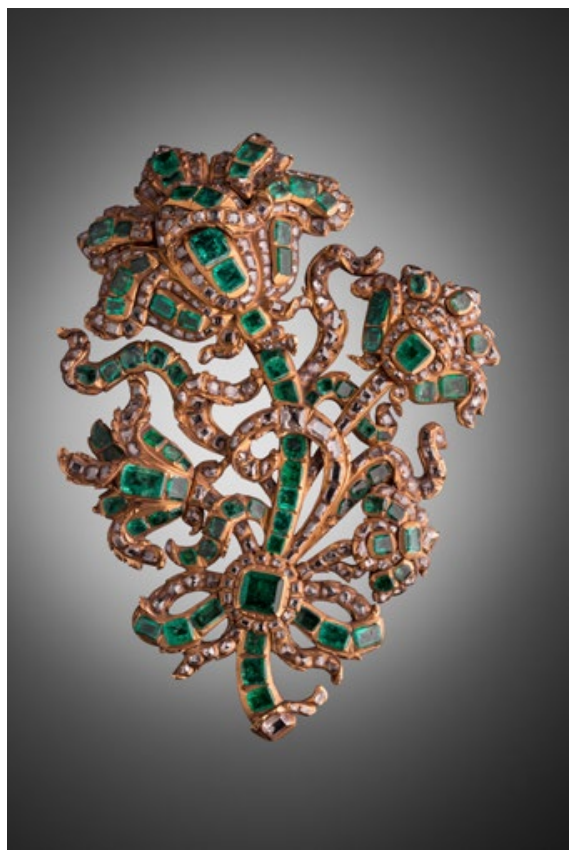

\section{$\rightarrow$ FIGURA 7.}

Orfebre siciliano. Arete. I696. Oro, diamantes, esmeraldas, esmalte. Regione Siciliana, Museo Regionale "Agostino Pepoli", Trapani

Fuente: fotografía de Maria Concetta Di Natale con concesión de MondoMostre.

Sicilia ${ }^{6}$, mencionamos la diadema de fabricación palermitana inspirada en los modelos españoles de finales del siglo XVII y de principios del XVIII, custodiada en la Galería Regional de Sicilia, del Palacio Abatellis en Palermo, procedente de la iglesia destruida de Santa María del Pueblo de los Mercedarios Descalzos, y las joyas de diversas tipologías y épocas del busto relicario de Santa Ágata en Catania. Entre los tesoros del relicario, muchos tienen forma de flor, como el donado por el Ayuntamiento de Catania en I675 o el obsequiado por la noble familia Tedesco (Di Natale, Gioielli 192), pero entre las joyas más llamativas está la de oro en forma de moño adornado con perlas y esmeraldas — combinación que se encuentra también en una homóloga joya del busto relicario de santa Venera en Acireale y en un collar perteneciente a una colección privada

6 Para otras joyas decoradas con esmeraldas, véase la tesis doctoral de Chiara Dell'Utri, así como Margiotta; Sciortino. 


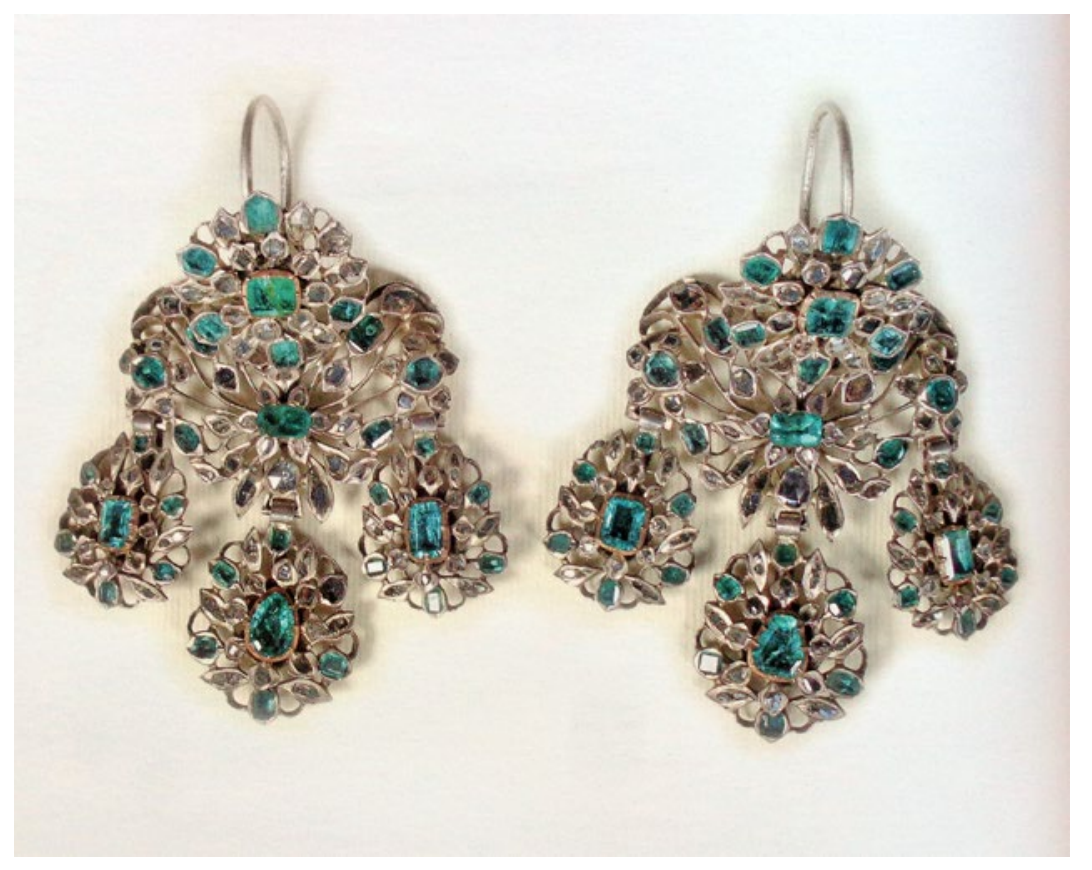

\section{$\rightarrow$ FIGURA 8 .}

Manufactura napolitana. Pendientes "girandoles". Tercer cuarto del siglo XVIII. Plata, esmeraldas y diamantes. Iglesia de san Benedicto, Conversano Fuente: fotografía de Rita Mavelli.

en Bagheria (Di Natale, "65-Collana” 35I) — de la mano de un orfebre siciliano de finales del siglo xviı o principios del xviı (Di Natale, Gioielli 2I4).

Sorprendentemente rico en esmeraldas es el ajuar de la Virgen del Rosario de Conversano, en Apulia, cuyo culto estaba ligado a los Acquaviva de Aragón, quienes probablemente fueron los donantes. Entre los distintos ejemplares que lo componen es preciso mencionar algunos broches que recogen los modelos publicados en los libros de Gilles Légaré (Livre des ouvrages d'orfévrerie) y de François Lefebvre (Livre des Fleurs), repertorios que lanzaron en toda Europa, hasta la segunda mitad del siglo XVIII, la moda de las joyas con gemas combinadas con perlas. Una de las piezas más relevantes del ajuar es el broche de plata, con esmeraldas y diamantes, que ha sido atribuido por Rita Mavelli al napolitano Matteo Treglia, y que era utilizado para adornar el corpiño del vestido del simulacro de la Virgen. El ajuar se completa con dos pulseras, un rico collar con colgante, un par de pendientes "girandoles" (figura 8), en plata, con esmeraldas y diamantes y de manufactura napolitana (Mavelli, "Sacri splendori” 303-316). 
El tesoro italiano más famoso y estudiado es el del patrón de Nápoles: san Genaro. Se trata de una de las más importantes colecciones en el mundo dentro de este género, ya sea por la preciosidad de las gemas, por el refinamiento de las elaboraciones, o por el valor histórico de las piezas ${ }^{7}$. Una de las obras más sorprendentes, considerada entre las diez maravillas del tesoro, es el collar del santo, que es el fruto de una compleja elaboración llevada a cabo entre los siglos XVII y XIX ${ }^{8}$. Fue encargada en 1679 por la Real Diputación del Tesoro de San Genaro al orfebre napolitano Michele Dato, quien la compuso con trece eslabones de oro articulables decorados con 904 diamantes, 490 rubíes y 140 esmeraldas. A pesar de que los diamantes son las piedras más presentes en el collar original, el ojo destaca más el verde de las esmeraldas. A este primer collar, en 1732, la Diputación hizo añadir una ciappa, un broche compuesto por siete esmeraldas, de las cuales la central es el berilo de mayores dimensiones; el estudio de las inclusiones ha permitido reconocer el origen colombiano de las esmeraldas, que se presentan líquidas bifásicas y numerosas trifásicas y multifásicas, y fluorescencia muy intensa de color rojo. A continuación se añadieron más joyas regaladas por reinantes y nobles, de las cuales destacamos la cruz de trece esmeraldas colombianas y diamantes donada en 1806 por José Napoleón Bonaparte al día siguiente de su toma de posesión sobre el trono de Nápoles, el broche en flor con diamantes y cuatro esmeraldas obsequiado en I832 por la reina María Cristina de Saboya y, por último, las comisiones de la Diputación del broche superior en I833 y de dos broches iguales colocados en los dos extremos laterales, por debajo del collar original del de Dato (Catello, "Collana” I34; Franchi, "Spille"; II7-II9; Giusti 53-62; Jorio, "Nove" III-II4; Marcon I2O-I42).

Otra obra maestra del tesoro de San Genaro, y de la orfebrería italiana, es la mitra del santo encargada por la Diputación a Matteo Treglia que la completó en I7I3, adornándola con 3326 diamantes, I68 rubíes y 198 esmeraldas de procedencia colombiana cortadas en peldaños. También en este caso el color preeminente es el verde de los berilos, que se destacan por la disposición simétrica pero sobre todo por sus dimensiones mayores que las demás gemas; las esmeraldas se consideraban las piedras más adecuadas para consagrar la unión entre la sacralidad del santo y el símbolo de la eternidad y del poder.

$7 \quad$ Sobre el tesoro de San Genaro y su capilla en la catedral de Nápoles existe una amplia literatura de la que se recuerda al menos Strazzullo, Jorio, Le meraviglie y Jorio y Recanatesi.

8 Véanse fotografías de las obras en el Museo del Tesoro de San Genaro, Nápoles, https://museosangennaro.it/tesoro/ 
A nivel macroscópico se notan las inclusiones, “jardines”, que gracias a una cuidadosa observación permiten suponer el origen neogranadino de las gemas. De los documentos del Archivo Histórico del Banco de Nápoles es posible deducir los precios de las piedras preciosas compradas por Treglia, quien por esmeraldas de 4 quilates pagaba 2 ducados el quilate (Acrovito I80-I8I; Paolillo I6I-I68).

Un objeto litúrgico particularmente importante en la Edad Moderna era el ostensorio, siempre en oro o plata, destinado a custodiar y a exhibir la hostia consagrada; no era raro que las piedras preciosas se emplearan para exaltar la centralidad de la especie eucarística, como sucede en la custodia en plata, hecha en $\mathbf{1 7 6 2}$, de la catedral de Lecce, cuyo resplandor está decorado con esmeraldas, diamantes y rubíes, o el coevo ostensorio con esmeraldas del tesoro de la catedral de Troya (Mavelli, Thesaurus 75-76).

Se debe señalar que las esmeraldas no llegaron a Italia solamente para ser engastadas allí, los documentos dan cuenta de joyas realizadas en el Nuevo Reino de Granada, como los anillos de esmeraldas solicitados por Juan del Castillo y Bartolomé de Olarián, promotores de la beatificación de Mariana de Jesús Paredes, la Azucena de Quito, con el fin de regalarlos junto a piedras bezoares, tazas de plata, mancerinas, cacao y tabaco a los religiosos que evaluaban la causa en Roma (AGI, $Q$, 590 A, carpeta I770-I776). En su amplio estudio sobre oribes y plateros, Marta Fajardo reflexiona sobre el estímulo que representó la presencia de estas gemas en el desarrollo de la orfebrería neogranadina (Fajardo, Oribes y plateros 84-85)

Haremos una reflexión sobre una obra existente en Colombia conocida por su extraordinaria belleza: la custodia ornamentada con esmeraldas y realizada para los jesuitas de la iglesia de San Ignacio de Bogotá, hoy en el Museo del Banco de la República, más conocida con el apelativo popular de "La Lechuga" (figuras 9 y io). Los estudios llevados a cabo sobre esta obra maestra de la orfebrería trasmiten que fue elaborada entre I700 y 1707 por el orfebre José de Galaz y por tres ayudantes, empleando hasta I 485 esmeraldas, además de un zafiro, 13 rubíes, 28 diamantes, 168 amatistas y 62 perlas. Se ha propuesto que el modelo compositivo de referencia para el ostensorio fue uno de los emblemas publicados por el agustino italiano Filippo Picinelli (I604-I678) en el libro Mundus Symbolicus, compuesto por una peana de forma polilobulada decorada con vegetales, sobre la que se levanta un ángel-telamón manierista que sostiene la rica teca radiada de la especie eucarística (Fajardo, "Orígenes" 7-I9). 

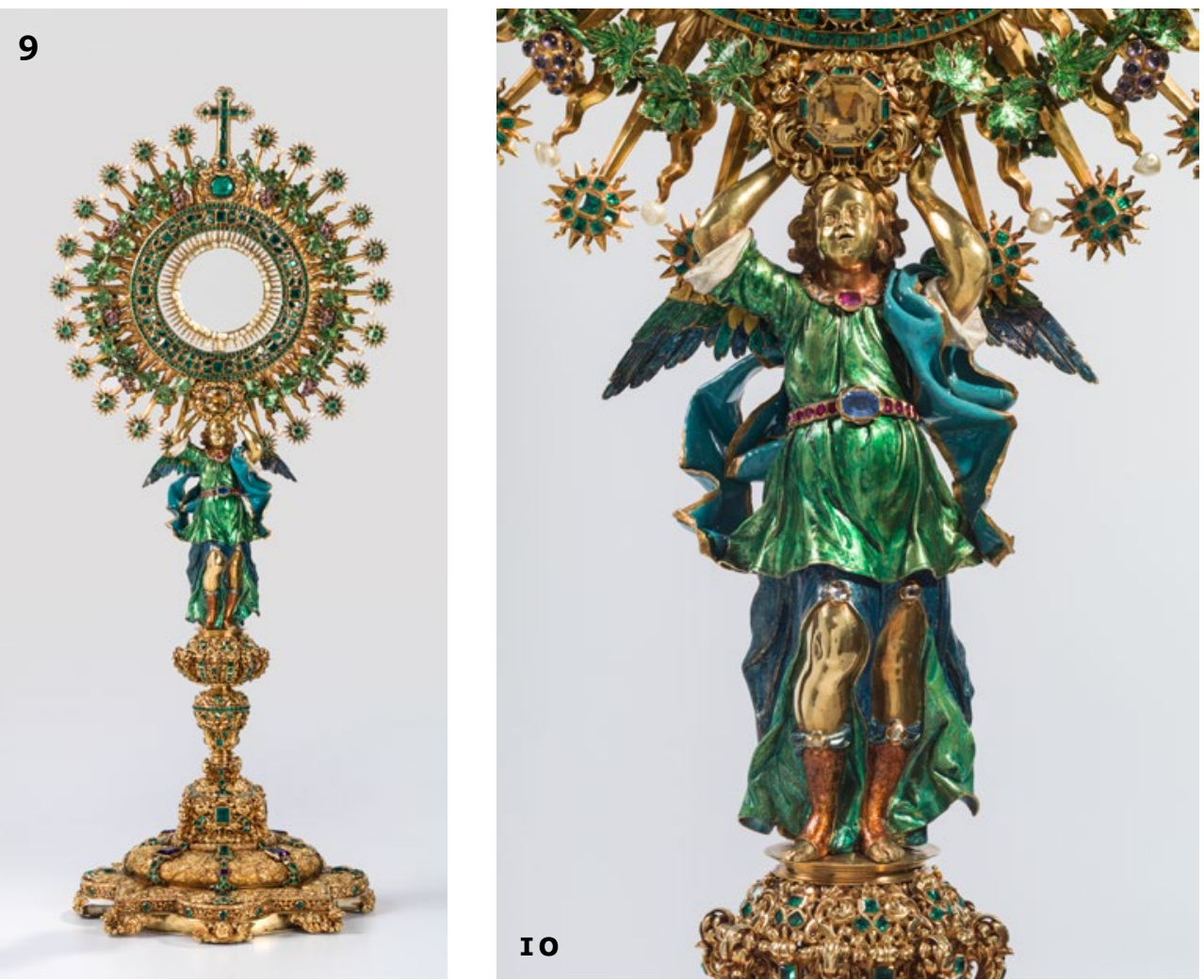

$\rightarrow$ FIGURA 9 .

José de Galaz. Custodia de la Compañía de Jesús de Santafé, "La Lechuga". I700-I707

Fuente: Colección de Arte del Banco de la República de Colombia.

- FIGURA IO.

José de Galaz. Detalle del ángel. Custodia de la Compañía de Jesús de Santafé, "La Lechuga". I700-I707

Fuente: Colección de Arte del Banco de la República de Colombia.

En apoyo al posible origen italiano del modelo nos parece útil plantear una comparación con el ostensorio de la catedral de Ruvo di Puglia, de un anónimo platero napolitano, realizado entre finales del siglo XVI y principios del XVII (figura II), y que presenta en el tronco un ángel manierista del todo análogo que sostiene la teca de "sol" (Di Palo II3-I32). Precisamente la comparación con esta obra, por las precisas y sorprendentes correspondencias en la figura angélica, nos lleva a plantear algunas dudas sobre el verdadero medio de transmisión del modelo del ostensorio colombiano, que podría no haber sido 
solamente el emblema de Picinelli sino la visión de un ejemplar italiano, quizás napolitano, probablemente perteneciente a la Compañía de Jesús de Bogotá, que poseía una amplia colección de objetos litúrgicos y obras de arte procedentes de Italia, como algunas lámparas de plata adquiridas en Boloña (ContrerasGuerrero y De Nicolo). Al mismo tiempo, en el estado actual de los estudios, tampoco es posible excluir la posibilidad de que José de Galaz haya realizado "La Lechuga" reutilizando componentes y partes de una antigua custodia italiana perteneciente a los jesuitas. La falta de más noticias sobre el maestro de Galaz, del que no se conocen otras obras, impide clarificar el punto, sin embargo, parece evidente una diferencia estilística entre el ángel manierista con el tronco y el pie polilobulado de gusto plateresco, pero sobre todo parece innegable la discontinuidad estilística con otras custodias, de gusto más claramente andino, que reutilizan la composición del ángel-telamón como los dos ejemplares existentes en la catedral de Tunja y en el Museo de Arte Arquidiocesano de Popayán (Fajardo, "Orígenes” I2-I3).

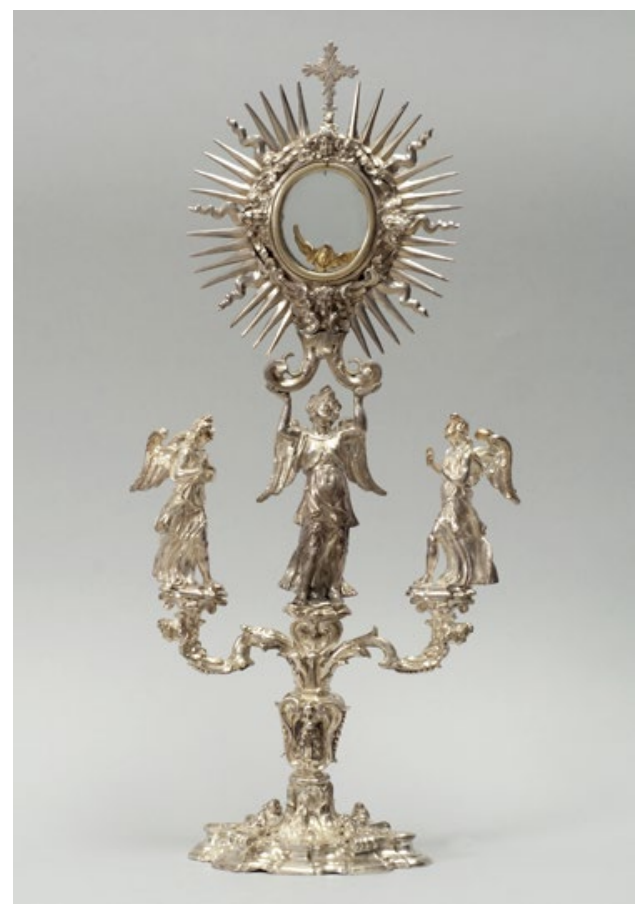

a FIGURA II.

Platero napolitano. Ostensorio. Finales del siglo XVI, inicios del siglo XVII. Plata. Catedral, Ruvo di Puglia

Fuente: fotografía de Francesco Di Palo. 


\section{Simbología}

Para concluir, se mencionarán brevemente las cualidades simbólicas atribuidas a las esmeraldas en Europa, con el fin de comprender las razones que, además de las estéticas, subyacen a su uso.

La atribución de cualidades curativas va a ser una constante en diferentes épocas y lugares, así, el Lapidario, compendio de traducciones de tratados árabes, encargadas por Alfonso X el Sabio, señala su poder de sanación, mientras que Leonard en Speculum lapidum la recomienda para frenar la lascivia y mejorar la memoria (Mínguez 562). En el siglo XIII, Vicente de Beauvais en Speculum Maius dedicó el capítulo IO2 a una recopilación de las propiedades que Dioscórides, Aristóteles y los autores de Natura rerum y Lapidario atribuyeron a estas gemas, entre las que mencionaban curar la hemitrítea y la epilepsia, fortalecer la vista, recuperar la memoria perdida, dar firmeza a los dientes sueltos, hacer llegar la menstruación y para los partos difíciles (Ramírez 505-506). Otros usos que se les dieron a estas gemas fueron los de erradicar la peste, anular los efectos de los venenos, otorgar elocuencia, combatir las tentaciones demoníacas y los malos pensamientos, como también para aplacar los temporales y las condiciones climáticas adversas (Di Natale, Gioielli 16). Además, se pensaba que las esmeraldas podían atraer la riqueza, alejaban la infidelidad del matrimonio y concedían el don de la profecía (Steingraber Io). Los lapidarios de Alfonso X relacionan la buena influencia de Mercurio y Júpiter sobre el que porte estas piedras (Pasero 350).

En cuanto a la importancia de la esmeralda dentro de la religión católica, sus referencias se remontan a la Biblia, siendo una de las piedras que componen el pectoral del juicio, ubicada en la primera fila junto al sardio y al topacio, y conformando con un rubí, un zafiro, un diamante, un ópalo, un ágata, una amatista, un crisólito, un ónice y un jaspe, un conjunto de doce, por lo que cada una debía estar tallada con el nombre de las tribus de Israel, según el Éxodo 28, I7. Por su parte, en Ezequiel 28, I3 se describe el Edén en el que vivía el hombre como un lugar lleno de cornalinas, topacios, diamantes, crisólito, ónices, jaspes, zafiros, malaquitas y esmeraldas en pendientes labradas en oro (Seoane I5II). La nueva Jerusalén del Apocalipsis 2I,I9 tiene esmeraldas como cimientos de la muralla, según la visión de san Juan (Seoane 1512), que, de acuerdo con los exegetas, representan los Evangelios que abren al mundo la elevación de la Fe; mientras que según Aimone d’Auxerre (siglo Ix), quién comenta este pasaje del Apocalipsis, la esmeralda es símbolo de Cristo que hace apacentar a sus fieles y da descanso eterno (Schoonhoven 77-78). 
En la España medieval, circulaba la leyenda de las esmeraldas de Solino, registrada en las Etimologías de Isidoro de Sevilla, que luego en un lapidario manuscrito adquiere una lectura religiosa, identificando a los cristianos con las esmeraldas; también Isidoro otorgaba una virtud de sosiego y serenidad al verde intenso de estas gemas (Pasero 343-345).

En cuanto a la emblemática, Ripa relaciona la esmeralda con la esperanza y la virginidad (Mínguez 565), y en la literatura Dante en el Purgatorio asocia las esmeraldas con el deseo del cielo expresado en la esperanza de la Fe y de la Justicia (Schoonhoven 84).

\section{Conclusiones}

El hallazgo de documentación vinculada al comercio de esmeraldas en Italia se ha dificultado en gran parte por su carácter ilícito.

A pesar de la existencia de tecnología para determinar las minas de origen de las esmeraldas, se ha tenido que afrontar la imposibilidad de desmontar las piedras de la mayoría de las joyas para poder realizar los análisis físicos. Las piezas pertenecen a ajuares religiosos que hacen parte del patrimonio artístico y devocional de las comunidades del sur de Italia que, cuando no las han musealizado, las custodian celosamente y solo las exhiben en ocasiones especiales.

Para superar estos obstáculos, ha sido indispensable la adopción de un enfoque interdisciplinario destinado a adquirir en el campo histórico-artístico las contribuciones ofrecidas por la historia económica, la geología, la antropología y la mineralogía, entre otras. El itinerario ha intentado ilustrar cómo las esmeraldas extraídas del Nuevo Reino de Granada llegaron a la Italia meridional para ser utilizadas en las producciones de joyería local. La belleza y el simbolismo de estas piedras las han hecho unas de las preferidas para ornamentar ajuares de santos o de la nobleza, según una moda que desde España influyó en los virreinatos italianos, sobre todo en el siglo XVII, mientras en el siglo XVIII los rubíes fueron progresivamente preferidos a las esmeraldas (Di Natale, Gioielli 238); la mayor dificultad para encontrar rubíes incrementó su valor comercial (Paolillo I64) - y por consiguiente también su atractivo- en comparación con los berilos que se extraían en grandes cantidades en Nueva Granada.

Otro aspecto que llama la atención es el desarrollo de técnicas de imitación de las esmeraldas que en las épocas virreinales se justificaba en la búsqueda de elementos ornamentales más baratos para clases menos pudientes, pero hoy en 
día a esta cualidad económica se le suma la intención de disminuir el impacto ambiental que genera la explotación minera y desincentivar el trabajo que bajo duras condiciones desempeńan los mineros; en algunos casos, el llamado a usar gemas falsas y otros materiales alternativos a la joyería tradicional también pretende mostrar rechazo a las situaciones de violencia que ha desatado la lucha por el poder y el dominio territorial, no solamente en el caso de las esmeraldas sino, en general, en las regiones que tienen algún tipo de riqueza minera.

A pesar del trayecto que debían cruzar las esmeraldas desde el Nuevo Reino de Granada hasta la península italiana, hay una alta probabilidad de que las gemas de este tipo que ornamentan la joyería religiosa de los siglos XVI al XVIII tengan origen neogranadino. Por un lado, generalmente las piedras preciosas colombianas tienen mayor calidad que las procedentes de India y, por otro, las minas de Habachtal de Austria, que estarían mucho más cercanas, no tuvieron una explotación constante debido a estar cubiertas por nieve gran parte del año, por lo que hasta el siglo xIX no hubo grandes beneficios; se debe recordar que las minas brasileñas, estadounidenses y africanas fueron descubiertas posteriormente. En este sentido, sería interesante continuar ahondando en los destinos específicos que tuvieron estas pied ras neogranadinas que despertaron tanto interés de la Corona como descontento por parte de los indígenas, la avaricia de los funcionarios, el establecimiento de redes de contrabando y la perfección de los oficios relacionados con la joyería.

La detección de esmeraldas neogranadinas en la Italia meridional plantea otros temas para indagar en el futuro, como lo es la evaluación de la frecuencia del uso de las esmeraldas en la Edad Moderna, en comparación con la época de la Roma Antigua, surtida por minas egipcias, y el Medioevo?.

9 Para la redacción de este ensayo se agradece a Vanessa Álvarez Portugal, Giovanni Boraccesi, Lauren Chen, Nicola Cleopazzo, Sigrid Castañeda, Roberta Cruciata, Christian de Letteriis, Maria Concetta Di Natale, Francesco Di Palo, Giuseppe Ingaglio, Gloria Martínez Leiva, María del Prado López, Rita Mavelli, Mario Panarello, Domenico Pisani y Diana Rodríguez. 


\section{$\infty$ \\ B I B L I O G R A F í A}

\section{FU E N T ES PRIMARIAS}

\section{A. Archivo}

Archivo General de Indias, Sevilla, España (AGI).

Indiferente $(I)$ I092

Quito (Q) $590 \mathrm{~A}$.

Archivo General de la Nación, Bogotá, Colombia (AGN).

Minas Boyacá (MB) sC. 38, 3, D. Iо.

\section{B. Impresos}

Acosta, Josef de. Historia natural y moral de las Indias, editado por Fermín del Pino-Díaz. Madrid: Consejo Superior de Investigaciones Científicas, 2008.

Aguado, Pedro. Recopilación historial. Bogotá: Imprenta Nacional, 1906.

Bossi, Luigi. Observations sur le vase que l'on conservait à Gênes sous le nom de Sacro Catino, et sur la note publiée surce vase par M. Millin. Turín: De l'imprimerie de Jean Giossi, I807.

Caliari, Pietro. Il nuovo lume delle gioie. Venecia: Iseppo Prodocimo, 1682.

De La Vega, Inca Garcilaso. Comentarios reales de los incas. Tomo I. Lima: Editorial Universo, 1968 .

Fernández de Piedrahita, Lucas. Historia general de las conquistas del Nuevo Reino de Granada. Amberes: Juan Bautista Verdussen, s. f.

Haüy, René-Just. Trattato dei caratteri fisici delle pietre preziose per determinare quando sieno lavorate, traducido por Luigi Configliachi. Milán: Giovanni Pirrotta, I819.

Murri, Vincenzo. Dissertazione critico-istorica sulla identità della Santa Casa di Nazarette ora venerata in Loreto. Loreto: Alessandro Carnevali, I791.

Maggio, Francesco Maria. S. Gaetano a’piedi della Immaculata Signora ouero Corona di dodici stelle, o Ragioni chiare e risplendenti a gli occhi di tutti. Nápoles: Novello de Bonis, 1670.

Pini, Vincenzo. Dizionario universale economico rustico, vol. 20. Roma: Michele Puccinielli, 1796. 
Pompa, Giuseppe, editor. Nuova enciclopedia popolare, ovvero Dizionario generale di scien$z e$, lettere, arti, storia, geografia, ecc., vol. ir. Turín: Stamperia sociale degli artisti tipografi, I849.

Robbio, Giovanni. Dizionario istorico ragionato delle gemme, delle pietre, e dé minerali, vol. 2. Nápoles: Angelo Cosa, I824.

Saggio di litografia ossia descrizione delle qualità e valore delle pietre, coagulazioni e dei metalli preziosi per istruzione dei gioiellieri e degli amatori. Milán: Giuseppe Pogliani, I82o.

Valmont de Bomare, Jacques-Christophe. Dizionario ragionato universale di storia naturale contenente la storia degli animali, vegetabili, e minerali..., vol. 32. Roma: Michele Puccinielli a Tor Sanguigna, I8or.

\section{I F U E N T E S S E C U N D A R I A S}

Acrovito, Armando. "Rubini, smeraldi, diamanti 3690 gemme di origine naturale". Le meraviglie del tesoro di San Gennaro: le pietre della devozione, editado por Paolo Jorio. Roma: De Luca, 2011, pp. I80-191.

Catello, Angela. "Collana pettorale di San Gennaro". Gioielli regali. Ori, smalti, coralli e pietre preziose nel Real Palazzo di Caserta tra XVIII e XX secolo, editado por Vega de Martini. Milán: Skira, 2005 , p. 8.

---. "Il primato di Napoli". Potere e liturgia. Argenti dell'età barocca in Terra di Bari, editado por Giacomo Lanzilotta. Bari: Adda editore, 2014, pp. 63-69.

CDTec (Centro de Desarrollo Tecnológico de la Esmeralda Colombiana). "Avances sobre el estudio de parámetros relacionados con el origen de esmeraldas colombianas", https://www.minenergia.gov.co/documents/ror80/23960525/Par\%C3\%Armetros+ Relacionados+con+Origen+Esmeraldas+Colombianas.pdf/67ca 4c3e-294b-4097$8679-d_{2} c_{34} f_{4}$ Iab6r

Contreras-Guerrero, Adrián y Francesco De Nicolo. "L'impronta italiana nell'arte neogranadina”. Esencias y pervivencias barrocas. Colombia en el Nuevo Reino de Granada, editado por Adrián Contreras-Guerrero y Jaime Humberto Borja. Sevilla: Universo Barroco Iberoamericano, 2021, pp. 287-339.

De Narváez McAllister, Daniel. "El tesoro de esmeraldas del galeón San José”. Semana, 22 de diciembre, 2016, https://www.semana.com/opinion/articulo/galeon-san-josecuantas-esmeraldas-habia-a-bordo/457577/

Dell'Utri, Chiara. “Un catalogo virtuale dell'oreficeria siciliana. La guida dei nuovi musei dello splendore". Tesis doctoral en Historia del Arte Medieval, Moderno y Contemporáneo en Sicilia, Università degli Studi di Palermo, 20 I. 
Di Natale, Maria Concetta. "65-Collana”. Splendori di Sicilia. Arti decorative in Sicilia, editado por Maria Concetta Di Natale. Milán: Charta, 200 I.

---. "Il Canonico Mondello e il Tesoro della Madonna di Trapani". OADI. Rivista dell'Osservatorio per le Arti Decorative in Italia, n. ${ }^{\circ}$ I 4, 2016, pp. I35-1 49.

--.. “I doni del viceré d'Ossuna alla Madonna di Trapani”. Cultura della guerra e arti della pace. Il III Duca di Osuna in Sicilia e a Napoli (I6II-I620), editado por Encarnación Sánchez García. Nápoles: Tullio Pironi, 2012, pp. 257-266.

---. Gioielli di Sicilia. Palermo: Flaccovio Editore, 2008.

---. “Ori e argenti del Tesoro della Cattedrale di Palermo”. Il Tesoro della Cattedrale di Palermo, editado por Maria Concetta Di Natale. Palermo: Flaccovio Editore, 2010, pp. 39-107.

Di Palo, Francesco. “L'ostensorio d'argento del 'tesoro' della Cattedrale di Ruvo”. Studi Rubastini. I luoghi, la storia, l'arte, l'architettura di Ruvo di Puglia, editado por Cleto Bucci. Ruvo di Puglia: Associazione Turistica Pro Loco, 2014, pp. I13-132.

Domínguez, Rafael. Historia de las esmeraldas de Colombia. Bogotá: Gráficas Ducal, 1965.

Fajardo de Rueda, Marta. Oribes y plateros en la Nueva Granada. León: Universidad de León, 2008.

---. "Orígenes, significados y creatividad en la orfebrería colonial: la custodia de la iglesia de San Ignacio de la Compañía de Jesús de Santafé (La Lechuga)”. Ensayos. Historia y Teoria del Arte, n'. 29, 2015, pp. 7-19.

Franchi, Claudio. "L'estetica del gioiello: arredo liturgico ed esibizione di grandezza". Le dieci Meraviglie del Tesoro di San Gennaro, pp. IоI-Iоз.

---. "Spille, croci, tosoni, fermagli: un capolavoro nato per caso". Le dieci Meraviglie del Tesoro di San Gennaro, pp. II7-II9.

García Zapata, Ignacio José y Laura Illescas Díaz. “Las cuatro partes del mundo conocidas: Europa, América, África y Asia, de la Sacristía de la Catedral Primada de Toledo. Obra del platero Lorenzo Vaccaro". Toletana, n. ${ }^{30,} 2014$, pp. I-23.

Gavrilenko, Egor. “Esmeraldas de los Urales (Rusia): Condiciones de formación y caracterización comparativa con las esmeraldas de otros orígenes”. Tesis de la Escuela Técnica Superior de Ingenieros de Minas, Madrid, 2003, http://oa.upm.es/299/1/06200309.pdf

Giuliani, Gaston, Alain Cheilletz, Carlos Arboleda, Víctor Carrillo y Simon Sheppard. "Geoquímica y origen de los depósitos de esmeraldas en Colombia”. Boletín de Geologia, vol. 21, n. 36 , 1999, pp. 7-13. 
Giuliani, Gaston, Marc Chaussidon, Henri-Jean Schubnel, Daniel Piat, Claire RollionBard, Christian France-Lanord, Didier Giard, Daniel de Narváez y Benjamin Rondeau. "Oxygen isotopes and emerald trade routes since Antiquity”. Science, vol. 287, n. $^{\circ} 5453$, pp. 63I-633, https://doi.org/I0.1126/science.287.5453.63I

Giusti, Laura. "Il collare di San Gennaro". Le meraviglie del tesoro di San Gennaro: le pietre della devozione, editado por Paolo Jorio. Roma: De Luca, 201 i, pp. 53-62.

Gri, Giampaolo. “Ori e Madonne. I gioielli votivi dei simulacri 'da vestire’ veneziani”. Donne Madonna Dee. Abito sacro e riti di vestizione, gioiello votivo, 'vestitrici': un itinerario antropologico in area lagunare veneta, editado por Riccarda Pagnozzato. Padova: Il Poligrafo, 2003, pp. 67-97.

IGE (Instituto Gemológico Español). “Tallas de las gemas”. s. f., https://ige.org/gemologia/ curso-basico-gemologia-online/capitulo-5-tallas-de-las-gemas/

Jorio, Paolo. "Nove sovrani e un popolo devoto per un gioiello lungo duecento anni". Le dieci Meraviglie del Tesoro di San Gennaro, pp. I08-iाs.

---, editor. Le meraviglie del tesoro di San Gennaro: le pietre della devozione. Roma: De Luca, $201 \mathrm{I}$.

Jorio, Paolo y Franco Recanatesi, editores. Le dieci Meraviglie del Tesoro di San Gennaro. Roma: Istituto Poligrafico e Zecca dello Stato Libreria dello Stato, 20 Io.

Lane, Kris. Colour of Paradise. Emeralds in the Age of the Gunpowder Empires. New Haven: Yale University Press, 2010, https://doi.org/I0.12987/yale/9780300161311.001.000I

Marcon, Renata. "Lucenti, brillanti, trasparenti sono gemme uniche e irripetibili". Le dieci Meraviglie del Tesoro di San Gennaro, pp. I20-142.

Margiotta, Rosalia Francesca. “'Iugalia aurea et argentea et bona mobilia’. Postille documentarie sui Ventimiglia di Gratteri”. OADI. Rivista dell'Osservatorioper le Arti Decorative in Italia, n. ${ }^{\circ}$ 19, 2019.

Martín de Retana, José María. El gran libro de la esmeralda. Bilbao: Editorial La Gran Enciclopedia Vasca, 1990.

Martínez Leiva, Gloria. “De profano a sacro: Mariana de Neoburgo y los Continentes de plata de Lorenzo Vaccaro en la Catedral de Toledo". Estudios de platería, editado por Jesús Rivas Carmona. Murcia: Universidad de Murcia, 20I6, pp. 36I-374.

Mavelli, Rita. "Oreficeria e argenteria sacra e profana”. La Puglia al tempo dei Borbone, editado por Clara Gelao. Bari: Adda editore, 2000, pp. 23I-244.

--.. "Le oreficerie garganiche nel panorama dell'ornamento femminile”. Ori del Gargano, editado por Anna Maria Tripputi y Rita Mavelli. Foggia: Claudio Grenzi Editore, 2005, pp. 25-54. 
---. "Sacri splendori. Il Tesoro della Madonna del Rosario e le sue gemme". Il Tesoro di San Benedetto in Conversano. Storia, arte, devozione e vita quotidiana nel Monstrum Apuliae, editado por Vito L'Abbte. Foggia: Claudio Grenzi Editore, 2017, pp. 303-324.

---. Thesaurus Thesauro conditur. Il Tesoro della Cattedrale di Troia. Gli argenti. Foggia: Claudio Grenzi Editore, 2017.

Mínguez, Víctor. "El lenguaje emblemático de las gemas". Literatura emblemática hispánica. Actas del I Simposio Internacional, editado por Sagrario López Poza. A Coruña: Universidade da Coruña, 1996, pp. 559-567.

Museo Diocesano. Catálogo. MuDi: la collezione del Museo Diocesano di Taranto. Taranto, 20I5.

Paniagua Pérez, Jesús. "Problemas en la extracción de esmeraldas en el Nuevo Reino de Granada: el informe de Pedro Puch (1766)". Historia Caribe, vol. vill, n. ${ }^{\circ} 23,2013$, pp. $17 \mathrm{I}-208$.

Paolillo, Ciro. "L'emozione di un salto nel tempo alla riscoperta di un maestro dell'oreficeria". Le dieci Meraviglie del Tesoro di San Gennaro, editado por Paolo Jorio. Nápoles: Ist. Poligrafico Dello Stato, 2010, pp. 159-169.

Pasero Díaz-Guerra, David. "La razón de ser de las gemas a través de los lapidarios en castellano (ss. XIII-XVI)”. Edad Media. Revista de Historia, n. ${ }^{\circ}$ 19, 2018, pp. 332-365, https:// doi.org/10.24197/em.19.2018.332-365

Pisani, Domenico. "Collana di San Bruno". Certosini a Serra San Bruno: ilpatrimonio storico e artistico, editado por Domenico Pisani y Fabio Tassone. Serra San Bruno: Certosa, 2015, pp. 262-263.

Puche Riart, Octavio. "La explotación de las esmeraldas de Muzo (Nueva Granada), en sus primeros tiempos". XI Congreso Internacional de AHILA. Liverpool: AHILA, I996, pp. 99-104.

Ramírez Cintas, Inmaculada. "La enseñanza de la química en el Speculum Maius de Vicente de Beauvais". Tesis, Universidad Nacional de Educación a Distancia (UNED), Departamento de Historia de la Educación y Educación Comparada, 2015.

Rojas Alfonso, Alberto Hernán. Bogotá capital mundial de la talla de esmeraldas. Bogotá: Servicio Nacional de Aprendizaje (SENA), 2017, https://issuu.com/wilsonrojas/docs/ ok_bogot_capital_mundial_de_la_talla_de_esmeralda

Ruotolo, Renato. "Alle origini della lavorazione delle pietre dure a Napoli: i cibori teatini". Ricerche sul '6oo napoletano: saggi in memoria di Oreste Ferrari 2007. Nápoles: Electa Napoli, 2008, pp. I05-II3. 
---. "Manifatture reali e gioielli di corte". Gioielli regali. Ori, smalti, coralli e pietre preziose nel Real Palazzo di Caserta tra XVIII e XX secolo, editado por Vega de Martini. Milán: Skira, 2005, pp. 4I-47.

Salvemini, Biagio. "Nuovi spazi mediterranei della 'decadenza'. Note su istituzioni, etiche e pratiche mercantili della tarda età moderna". Storica, n. ${ }^{\circ}$ 5I, 201 I, pp. 7-5I.

Scandale, Eugenio, editor. La Madonna Odegitria di Bari ed isuoi preziosi ornamenti. Foggia: Claudio Grenzi Editore, 2008.

Sciortino, Luisa. "I tesori perduti del Duomo di Monreale nell'inedito inventario della Maramma della Cattedrale del I838”. OADI. Rivista dell'Osservatorio per le Arti Decorative in Italia, n. ${ }^{\circ}$ 2, 2010 , pp. 147-221.

Schoonhoven, Erik. "Fra Dio e l'imperatore: il simbolismo delle pietre preziose nella Divina Commedia". Dante: Rivista internazionale di studi su Dante Alighieri, vol. III, 2006, pp. 69-93.

Seoane Dovigo, María. "El simbolismo de las gemas en la trayectoria amorosa de Felismena en la Diana de Jorge de Montemayor". Actas del IV Congreso Internacional Siglo de Oro (AISO), vol. I, editado por María Cruz García de Enterría y Alicia Cordón Mesa. Alcalá de Henares: Universidad de Alcalá, 1996, pp. 1509-1517

Steingraber, Erich. L'arte del gioiello in Europa dal Medioevo al Liberty. Florencia: Edam, 1965.

Strazzullo, Francesco. La Real cappella del Tesoro di S. Gennaro: documenti inediti. Nápoles: Società editrice napoletana, 1978 .

Tafur Garcés, Leonardo. "Santa Ana de los Caballeros y la custodia de Benvenuto Cellini”. Boletín de Historia y Antigüedades, n. ${ }^{\circ}$ 295-296, vol. XXvi, 1939, pp. 405-409.

Tripputi, Anna Maria. "Quando la Madonna si “indora”. Ori del Gargano, editado por Anna Maria Tripputi y Rita Mavelli. Foggia: Claudio Grenzi Editore, 2005, pp. 96-105.

Trivellato, Francesca. The Familiarity of Strangers. The Sephardic diaspora, Livorno, and cross-cultural trade in the Early Modern Period. New Haven-Londres: Yale University Press, 2009 . 